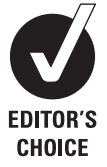

CHOICE

\title{
Tumour necrosis factor antagonist use and associated risk reduction of cardiovascular events among patients with rheumatoid arthritis
}

\author{
Jeffrey D Greenberg, ${ }^{1}$ Joel M Kremer, ${ }^{2}$ Jeffrey R Curtis, ${ }^{3}$ Marc C Hochberg, ${ }^{4}$ \\ George Reed ${ }^{5}$ Peter Tsao, ${ }^{6}$ Michael E Farkouh, ${ }^{7}$ Adeel Nasir, ${ }^{1}$ Soko Setoguchi, ${ }^{8}$ \\ Daniel H Solomon, ${ }^{6,8}$ on behalf of the CORRONA Investigators
}

\begin{abstract}
See Editorial, p561
- A supplementary table is published online only. To view this file please visit the journal online (http://ard.bmj.com)
\end{abstract}

'Department of Rheumatology, New York University Hospital for Joint Diseases, New York, New York, USA

2Division of Rheumatology, Albany Medical College, Albany, New York, USA

${ }^{3}$ Division of Clinical Immunology and Rheumatology, University of Alabama at Birmingham, Birmingham, Alabama, USA ${ }^{4}$ Division of Rheumatology and Clinical Immunology, University of Maryland, Baltimore,

Maryland, USA

${ }^{5}$ Division of Preventive and Behavioral Medicine, University of Massachusetts School of Medicine, Worcester Massachusetts, USA

${ }^{6}$ Division of Rheumatology, Immunology, and Allergy, Brigham and Women's Hospital, Boston, Massachusetts, USA ${ }^{7}$ Clinical Trials Unit, Mount Sinai Heart, New York, New York, USA

${ }^{8}$ Division of

Pharmacoepidemiology, Brigham and Women's Hospital, Boston, Massachusetts, USA

\section{Correspondence to}

Dr Jeffrey D Greenberg,

Department of Rheumatology,

New York University Hospital for Joint Diseases, 301 East 17th Street, Suite 1410, New York, NY 10003, USA;

jeffrey.greenberg@nyumc.org

Accepted 3 October 2010

Published Online First

24 November 2010

\begin{abstract}
Objective To examine the association of cardiovascular events with tumour necrosis factor (TNF) $\alpha$ antagonist use compared with non-biological disease-modifying antirheumatic drug (DMARD) utilisation in patients with rheumatoid arthritis (RA).

Methods The study population included 10156 patients enrolled in the Consortium of Rheumatology Researchers of North America RA registry. Three study cohorts were defined based on three mutually exclusive drug use categories, including TNF antagonists, methotrexate and other non-biological DMARDs. HR were calculated adjusting for cardiovascular risk factors, RA disease characteristics and prednisone use. The primary study outcome was a composite of non-fatal myocardial infarction (MI), transient ischaemic attack (TIA) or stroke and cardiovascular-related death.
\end{abstract}

Results There were 88 cardiovascular events, including $26 \mathrm{Ml}, 45 \mathrm{TIA} /$ strokes and 17 cardiovascular-related deaths. After adjusting for age, gender, cardiovascular risk factors and RA disease characteristics, patients using a TNF antagonist experienced a reduced risk of the primary composite cardiovascular endpoint (HR 0.39, $95 \% \mathrm{Cl} 0.19$ to 0.82 ) compared with users of nonbiological DMARDs. Methotrexate was not associated with a reduced risk (HR 0.94, 95\% $\mathrm{Cl} 0.49$ to 1.80). Prednisone use was associated with a dose-dependent increased risk $(p=0.04)$. The risk reduction associated with TNF antagonists was also observed for non-fatal cardiovascular events (HR 0.35, 95\% $\mathrm{Cl} 0.16$ to 0.74 ).

Conclusion TNF antagonist use was associated with a reduced risk of cardiovascular events in patients with $\mathrm{RA}$.

Epidemiological studies have established that rheumatoid arthritis (RA) is associated with an increased risk of premature cardiovascular disease including myocardial infarction (MI) and cardiovascular-related mortality. ${ }^{1-5}$ This heightened risk is not completely attributable to traditional cardiovascular risk factors, and there is growing evidence that inflammatory mediators contribute to the risk. ${ }^{6-8}$ Moreover, recent studies indicate that inflammation plays a key role in atherosclerosis among patients without an underlying inflammatory disease. ${ }^{9-11}$

Tumour necrosis factor (TNF) $\alpha$ antagonists have been a major advance in the treatment of RA, with randomised controlled trials demonstrating significant reductions in pain and improvement in function. ${ }^{12} 13$ TNF antagonists reduce levels of pro-inflammatory cytokines in synovial tissue and in the systemic circulation. ${ }^{14}$ In addition to reducing C-reactive protein in patients with RA, TNF antagonists modify established cardiovascular risk factors, including insulin resistance and lipid metabolism. ${ }^{15-17}$ However, trials of TNF antagonists have not been designed to study cardiovascular endpoints and have insufficient power to detect modest benefits in relatively uncommon outcomes, such as MI.

Whereas short-term assessments of the effect of TNF antagonists on surrogate markers of cardiovascular risk have demonstrated beneficial effects, ${ }^{18-20}$ published studies examining the association of TNF antagonists with the risk of cardiovascular events have predominantly failed to demonstrate a reduced risk. ${ }^{5}$ 21-23 Investigators from the UK concluded that TNF antagonists do not reduce the risk of MI overall, but may reduce the risk in the subset of patients achieving a clinical response. ${ }^{21}$ However, promising results for improving cardiovascular outcomes with TNF antagonist use have been reported by two European studies. ${ }^{24} 25$

The objective of the present study was to investigate the incidence of cardiovascular events among RA patients treated with TNF antagonists, methotrexate, other non-biological disease-modifying antirheumatic drugs (DMARDs) and prednisone in a large US-based cohort. We utilised data from the Consortium of Rheumatology Researchers of North America (CORRONA) registry.

\section{METHODS}

\section{Study design}

We conducted a longitudinal cohort study of RA patients enrolled in the CORRONA registry. Details of the CORRONA registry have been published previously. ${ }^{26} 27$ Both participating rheumatologists and patients complete detailed clinical assessment forms at enrolment and follow-up study visits, which are completed at the time of a routine clinical encounter. Drug utilisation data are captured at each visit for both non-biological and biological DMARDs, as well as established physician and patient-derived RA disease activity outcomes, such as individual components of the American College of Rheumatology response criteria. ${ }^{28}$ Comorbidities, including cardiovascular risk factors and incident adverse events are also recorded by the treating rheumatologist. 


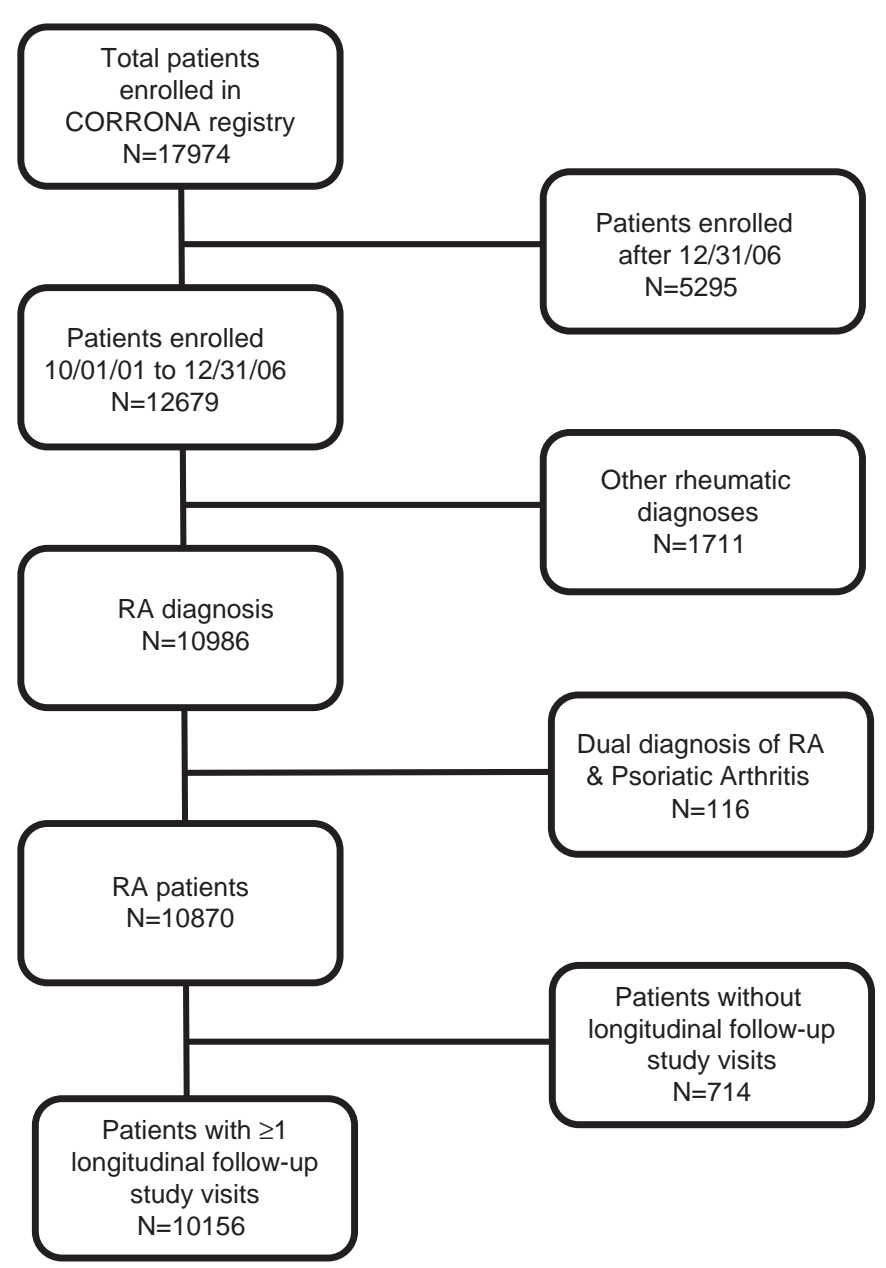

Figure 1 Study population flowchart. RA, rheumatoid arthritis.

Follow-up assessments are performed during routine clinic visits approximately every 3 months, at which time interim events and medication changes are recorded. The study was approved by the institutional review boards of participating academic sites and a central institutional review board for communitybased private sites and all patients sign informed consent before participation.

\section{Study population}

The study population included patients enrolled in the CORRONA registry from 1 October 2001 until 31 December 2006 who were diagnosed with RA by their treating rheumatologist and had a minimum of two study visits. The CORRONA registry includes a network of 268 participating academic and community rheumatologists at 103 sites in 35 states within the USA. CORRONA is a disease-based registry. Access to and use of biological DMARDs in the USA varies depending on patient insurance and study period. In our study, TNF antagonists were prescribed to $43 \%$ of the study population. All patients with a diagnosis of RA or psoriatic arthritis treated by participating rheumatologists are eligible. At enrolment, current drug utilisation is captured, and new drug starts are captured whenever prescribed during follow-up. Patients with a diagnosis of psoriatic arthritis were excluded from this study. Patients with a previous history of cardiovascular disease, as well as patients with no previous cardiovascular history, were included in the study. A flow chart of eligible and selected patients for this study can be found in figure 1 .

\section{Endpoints}

The primary outcome for this study was a composite cardiovascular endpoint of incident non-fatal MI, non-fatal stroke or transient ischaemic attack (TIA) and cardiovascular-related death. Secondary outcomes included non-fatal MI and stroke/ TIA evaluated as a composite of non-fatal cardiovascular events, as well as individual outcomes. Incident cardiovascular events were defined as physician-reported cardiovascular events ascertained at a study visit that were subsequently confirmed by the reporting investigator site. Deaths were reported by the investigator site as part of the study protocol, and the cardiovascularrelated attribution of the death was determined by the treating rheumatologist.

After confirmation of the reported events by the treating rheumatologist, the validity of the physician-confirmed cardiovascular events was determined by a three-person adjudication committee consisting of two board-certified cardiologists and an internal medicine specialist. For this adjudication, we requested hospital records for all cardiovascular events reported during the study period. The adjudication committee reviewed all cases of MI, stroke, TIA and cardiovascular-related deaths reported by participating rheumatologists for which hospital records or source documents were available. All events were classified into one of four possible categories: definite, probable, possible and unlikely cardiovascular events. Events adjudicated as definite or probable were considered as true events for the purposes of validation. Case definition criteria for $\mathrm{MI}$ and TIA/stroke were applied by the adjudication committee as previously defined and implemented in a multicentred clinical trial with cardiovascular adjudication. ${ }^{29}$

Hospital records including discharge summaries were obtained on the majority $(42 / 71,59 \%)$ of the confirmed non-fatal cardiovascular events. For the 42 adjudicated cardiovascular events, 14 $(33 \%)$ events were adjudicated as definite, $26(62 \%)$ as probable, one $(2 \%)$ as possible and one $(2 \%)$ as unlikely. Definite and possible events were categorised as true events, with a positive predictive value of $95 \%$ for cardiovascular events. The positive predictive value for MI was $94 \%$ and $96 \%$ for stroke/ TIA. Death certificates were not collected as part of the study protocol, and thus case validation was limited to non-fatal cardiovascular events.

\section{RA treatment exposure}

IndividualDMARD utilisation data, including both non-biological and biological agents, were collected prospectively using clinical assessment forms completed at each study visit. The index date for calculating drug exposure was the first recorded study visit at which the physician reported prescribing the drug, except for subjects with non-biological or biological DMARD use noted at baseline. Ongoing non-biological or biological DMARD use at baseline was included in the exposure assessment. A sensitivity analysis considered only new use of DMARDs. If the drug was started or stopped between study visits, the midpoint of the time interval was utilised. This assumption was varied in sensitivity analyses. When DMARD exposures changed during follow-up, these subsequent exposure periods were included. The same subject could thus contribute person time to more than one exposure category, each with a distinct index date.

We categorised DMARD use into the following hierarchy of three mutually exclusive exposure categories: (1) TNF antagonist use (monotherapy or combination therapy with non-biological DMARDs including methotrexate); (2) methotrexate use (monotherapy or combination therapy with other non-biological DMARDs but not TNF antagonists); or (3) other non-biological 
DMARDs, excluding methotrexate and TNF antagonists. Individual patients could contribute person-years of exposure to different drug cohorts over time, but drug exposure for each study interval was assigned to one of the three categories. Other non-biological DMARDs excluding methotrexate were grouped together.

Because prednisone was prescribed to patients across the three study cohorts, prednisone use was evaluated as a covariate at the index date and stratified into three dose categories: (1) nonuse; (2) use of 1-7 mg daily; and (3) $\geq 7.5 \mathrm{mg}$ daily. Person time reflecting utilisation of other biological agents including anakinra, abatacept and rituximab were excluded from the analysis.

\section{Other covariates}

The following covariates were evaluated for the statistical models: demographics (age, gender, race, body mass index, education), cardiovascular risk factors (physician-reported history of hypertension, diabetes, previous MI, stroke or coronary artery disease, treated dyslipidaemia, current tobacco use) and RA-specific factors (rheumatoid factor status, RA disease duration, presence of nodules, disease activity level and physical function defined by the modified health assessment questionnaire score). ${ }^{30}$ The disease activity score in 28 joints (DAS28) utilising the physician-derived 28 tender and swollen joint counts, patient global assessment visual analogue scale score and erythrocyte sedimentation rate (ESR) was calculated as previously defined. ${ }^{31}$ Non-steroidal anti-inflammatory drug (NSAID) covariates included naproxen, other non-selective NSAID and cyclooxygenase- 2 selective inhibitors. Aspirin was also included. All covariates were evaluated at the visit coinciding with the index date and were updated if subjects changed exposure category.

\section{Statistical analysis}

Characteristics of the three exposure cohorts were compared, allowing subjects to contribute person time to more than one cohort. Incidence rates were calculated for each DMARD exposure cohort. All patients were followed until one of the following occurred: end of the study period, withdrawal from the registry, a non-fatal cardiovascular outcome or death. Cox proportional hazard regression models were constructed to assess the RR associated with TNF antagonist use and methotrexate use compared with the non-biological DMARDs. Standard errors were corrected using a robust sandwich estimator to account for multiple observations from the same subject.

The primary model examined the composite cardiovascular endpoint, and secondary models examined non-fatal events as a composite, as well as MI and TIA/stroke individually. All incident cases of MI, TIA/stroke and cardiovascular-related deaths occurring within 180 days of the last study visit were included in the primary model. Age, gender, cardiovascular risk factors, NSAID covariates, prednisone dose and DMARD exposure cohorts were included in all models. RA-related factors were considered for model inclusion based on a backward selection routine using a p value threshold to enter the model of 0.2 . RA-related factors with a $p$ value of less than 0.1 were included in all final models. Fully adjusted models were run for the composite endpoint (including cardiovascular-related deaths), nonfatal MI and TIA/stroke as a composite outcome and then MI and TIA/stroke as individual outcomes.

A number of additional sensitivity analyses were conducted. First, we limited the analysis to patients with hospital records that were adjudicated to have definite or probable cardiovascular events. Second, we limited the analysis to new use periods for the DMARD exposures, rather than ongoing or prevalent periods. A third sensitivity analysis limited the cohort to rheumatoid factor-positive RA subjects. Fourth, we re-ran the primary model, forcing in baseline clinical disease activity index (CDAI) scores. We selected CDAI to minimise the number of patients that would be excluded due to missing ESR or C-reactive protein values. Fifth, we excluded patients with previous cardiovascular disease from the model. Sixth, we re-ran the model and broke out the TNF antagonist cohort into monotherapy versus combination therapy (concomitant non-biological DMARD use). Because precise dates were not available for the start and stop dates for some DMARD use periods and for some cardiovascular events, we varied these dates to test our assumptions. In addition, we varied the allowable period between the last visit with a reported drug exposure and a cardiovascular-related death; 180 days was chosen for the primary analysis, with shorter and longer periods allowed in sensitivity analyses. Additional sensitivities varying the drug exposure category for patients

Table 1 Baseline characteristics according to medication exposure period

\begin{tabular}{|c|c|c|c|}
\hline & $\begin{array}{l}\text { TNF } \\
\text { antagonist* } \\
\text { ( } N=4684)\end{array}$ & $\begin{array}{l}\text { Methotrexate }{ }^{\dagger} \\
(\mathrm{N}=4969)\end{array}$ & $\begin{array}{l}\text { Non-methotrexate } \\
\text { non-biological } \\
\text { DMARDs ( }=1785)\end{array}$ \\
\hline No of unique patients ${ }^{\ddagger}$ & 4361 & 4016 & 1406 \\
\hline \multicolumn{4}{|l|}{ Demographics } \\
\hline Female gender & $3598(76.9)$ & $3687(17.1)$ & $1343(75.3)$ \\
\hline Age (years, mean $( \pm S D))$ & $56.3 \pm 15.1$ & $59.09 \pm 14.6$ & $58.6 \pm 14.3$ \\
\hline Race (white) & $4244(90.6)$ & $4555(91.7)$ & $1662(93.1)$ \\
\hline Educational level (college) & $2314(52.8)$ & $2128(45.7)$ & $821(48.7)$ \\
\hline $\mathrm{BMI}$, mean ( $\pm \mathrm{SD})$ & $28.1 \pm 9.0$ & $28.0 \pm 9.1$ & $27.5 \pm 8.6$ \\
\hline \multicolumn{4}{|l|}{ RA-related variables } \\
\hline $\begin{array}{l}\text { Duration of RA, median (years } \\
\text { (IQR)) }\end{array}$ & $8(13)$ & $6(12)$ & $6(12)$ \\
\hline Rheumatoid factor positive & $2319(74.0)$ & 2456 (70.9) & $900(71.8)$ \\
\hline Radiographic erosions & $1387(57.4)$ & $1288(48.7)$ & $399(43.3)$ \\
\hline Rheumatoid nodules & $1115(23.8)$ & $915(18.4)$ & $349(19.5)$ \\
\hline DAS28 & $3.7(1.8)$ & $3.7(1.7)$ & $3.6(1.7)$ \\
\hline CDAI (median (IOR)) & $12.4(18.9)$ & $10.8(18.1)$ & $9.5(16.6)$ \\
\hline Modified HAQ (median (IQR)) & $0.25(0.63)$ & $0.13(0.63)$ & $0.13(0.5)$ \\
\hline \multicolumn{4}{|l|}{ Cardiovascular risk factors } \\
\hline Diabetes & $259(5.5)$ & $287(5.8)$ & $92(5.2)$ \\
\hline Hypertension & $1046(22.3)$ & $1202(24.2)$ & $433(24.3)$ \\
\hline Dyslipidaemia (treated) & $416(8.9)$ & $471(9.5)$ & $171(9.6)$ \\
\hline Current smoking use & $754(16.1)$ & $753(15.2)$ & $296(16.6)$ \\
\hline Family history of MI & $41(0.9)$ & $52(1.1)$ & $19(1.1)$ \\
\hline Previous CAD & $213(4.6)$ & $243(4.9)$ & $100(5.6)$ \\
\hline Previous history of MI & $139(3.0)$ & $202(4.1)$ & $83(4.7)$ \\
\hline Previous TIA/stroke & $229(4.9)$ & $300(6.0)$ & $116(6.5)$ \\
\hline \multicolumn{4}{|l|}{ Prednisone use } \\
\hline None & $2852(60.9)$ & $3052(61.4)$ & $1130(63.3)$ \\
\hline $1-7 \mathrm{mg}$ & $1355(28.9)$ & $1434(28.9)$ & $465(26.1)$ \\
\hline$\geq 7.5 \mathrm{mg}$ & $477(10.2)$ & $483(9.7)$ & $190(10.6)$ \\
\hline \multicolumn{4}{|l|}{ Other medications } \\
\hline Aspirin use & $673(14.4)$ & $821(16.5)$ & $325(18.2)$ \\
\hline Naproxen & $184(3.9)$ & $201(4.1)$ & $67(3.8)$ \\
\hline Other non-selective NSAID & $1061(22.7)$ & $1091(22.0)$ & $443(24.8)$ \\
\hline COX-2-selective NSAID & $1192(25.5)$ & $1185(23.7)$ & $405(22.7)$ \\
\hline
\end{tabular}

All values represent exposure periods expressed as $\mathrm{N}(\%)$ unless otherwise specified. * Monotherapy or combination therapy with any other disease-modifying antirheumatic drug (DMARD), including methotrexate.

${ }^{\dagger}$ Monotherapy or combination therapy with any other non-biological DMARD. ${ }^{\ddagger}$ Excludes patients without any DMARD therapy $(\mathrm{N}=373)$ during study period. $\mathrm{BMI}$, body mass index; $\mathrm{CAD}$, coronary artery disease; CDAl, clinical disease activity index; COX-2, cyclooxygenase 2; DAS28, disease activity score in 28 joints; HAO, health assessment questionnaire: MI, myocardial infarction; NSAID, non-steroidal anti-inflammatory drug; RA, rheumatoid arthritis; TIA, transient ischaemic attack; TNF, tumour necrosis factor. 
who switched categories during the study period were also performed. All analyses were conducted using SAS version 9.0.

\section{RESULTS}

A total of 10156 RA patients was followed for a median of 22.9 months. The study population was $75 \%$ female, mean (SD) age was 59 (13) years and $72 \%$ were rheumatoid factor positive. The median (IOR) interval between study visits was 4.0 (3.0-5.5 months). Baseline characteristics of the three cohorts are summarised in table 1.

Among 11438 patient exposure periods, there were 4684 exposure periods to TNF antagonists, 4969 exposure periods to methotrexate and 1785 exposure periods to other non-biological DMARDs. More than two-thirds of patients in each drug category did not switch categories, including $72 \%$ of anti-TNF users, $78 \%$ of methotrexate users and $68 \%$ of non-biological DMARD users. The majority of the exposure periods included no prednisone use ( $\mathrm{N}=6689)$. There were 3141 DMARD exposure periods with the use of prednisone 1-7 mg daily and 1090 exposure periods with prednisone $7.5 \mathrm{mg}$ or greater daily. The proportion of patients with previous anti-TNF exposure was $12.9 \%$ for anti-TNF users, $32.7 \%$ for methotrexate users and $20.9 \%$ for non-biological DMARD users. Postdiscontinuation exposure time in a different drug exposure category represented a minority of person time, including $5 \%$ of total person time for anti-TNF users, $18 \%$ for methotrexate users and $25 \%$ for non-biological DMARD users. The baseline characteristics of patients who did not exit compared with those who did exit the registry were reasonably similar, including the proportion of anti-TNF users ( $46 \%$ vs $51 \%$ ). During the study period, there were 88 composite cardiovascular events, including 26 MI, 45 stroke/TIA and 17 cardiovascular-related deaths. Incidence rates per 1000 person-years for the composite and individual cardiovascular events for the three drug classes are shown in table 2. For the composite endpoint, the incidence rate was 7.51 (95\% CI 3.95 to 11.07 ) for the reference group of non-biological DMARD users, 6.73 (95\% CI 4.83 to 8.63) for methotrexate users and 2.93 (95\% CI 1.74 to 4.13 ) for patients prescribed TNF antagonists.

The results of the fully adjusted model for the composite cardiovascular endpoint demonstrated that TNF antagonists were associated with a reduced risk (HR $0.39,95 \%$ CI 0.19 to 0.82 ) but not methotrexate (HR $0.94,95 \%$ CI 0.49 to 1.80), using the non-biological DMARDs as the reference cohort (see table 3). In the same model, prednisone use was associated with a dosedependent risk of cardiovascular events. Compared with nonuse of prednisone, prednisone dosages of 1-7 mg daily (HR 1.78, $95 \%$ CI 1.06 to 2.96 ) and dosages of $7.5 \mathrm{mg}$ or greater daily (HR $2.62,95 \%$ CI 1.29 to 2.96 ) were associated with progressively increasing risk ( $p$ value for trend 0.04). Results of the full model for all covariates can be found in supplementary table 1 (available online only).

Results of fully adjusted models for the secondary cardiovascular endpoints are summarised in table 4.

For non-fatal MI and TIA/stroke outcomes as a composite, the use of TNF antagonists was associated with reduced risk (HR $0.35,95 \%$ CI 0.16 to 0.74 ). For the individual cardiovascular outcomes, the use of TNF antagonists was associated with a reduced MI risk (HR 0.24, 95\% CI 0.06 to 0.95 ) and a trend towards a reduced risk of TIA/stroke (HR 0.44, 95\% CI 0.18 to 1.09). Additional sensitivity analyses are summarised in table 5 . The inclusion of baseline CDAI did not substantially alter the risk estimate, nor did limiting to new users or excluding patients with previous cardiovascular disease. The inclusion of baseline DAS28-ESR produced similar results. The risk estimates observed for all of the sensitivity models were consistent with the primary model, showing risk reduction associated with the use of TNF antagonists compared with non-biological DMARDs.

\section{DISCUSSION}

Despite the published evidence of a heightened cardiovascular risk for RA patients, few studies have investigated therapeutic strategies to reduce this risk. In our study, we found that treatment with TNF antagonists, but not methotrexate, was associated with a reduced risk of cardiovascular events compared with non-biological DMARDs. This risk reduction was observed for both MI and TIA/stroke as individual outcomes. Conversely, we observed a dose-dependent risk for patients prescribed prednisone. These data indicate that TNF antagonists may represent a therapeutic strategy to attenuate the heightened cardiovascular risk experienced by RA patients.

The mechanism by which TNF antagonists may reduce cardiovascular risk in RA patients remains speculative, although the pleiotropic effects of TNF $\alpha$ on the cardiovascular system and inflammatory pathways have been well described. ${ }^{14}{ }^{32-34}$ TNF $\alpha$ has been detected in the endothelium, smooth muscle cells and macrophages associated with coronary atherosclerotic plaques. ${ }^{32}$ In addition, it has been observed that TNF $\alpha$ can be upregulated in the myocardium in animal models after transient myocardial ischaemia and reperfusion. ${ }^{33}$ While the precise mechanism remains unclear, further evidence of the importance of TNF $\alpha$ in the prognosis after infarction has emerged from work by other investigators, demonstrating that plasma concentrations of TNF $\alpha$ and other cytokines may be independent predictors of cardiovascular events. ${ }^{10} 35$ Based on these studies and related work, it has been suggested that TNF antagonists may serve to stabilise atheromatous plaques and prevent rupture. ${ }^{11} 34$ An additional proposed mechanism for a beneficial effect of TNF antagonists has been suggested by studies demonstrating an improvement of flow-mediated vasodilation and endothelial function. ${ }^{18} 36$

Table 2 Incidence rates of cardiovascular events by medication exposure

\begin{tabular}{|c|c|c|c|c|c|c|c|c|c|c|c|c|}
\hline & \multicolumn{3}{|l|}{ MI } & \multicolumn{3}{|c|}{ TIA/stroke } & \multicolumn{3}{|c|}{ Cardiovascular-related death } & \multicolumn{3}{|c|}{ Composite cardiovascular events* } \\
\hline & Event & $\begin{array}{l}\text { Person years } \\
\text { of exposure }\end{array}$ & $\begin{array}{l}\text { Incidence rate } \\
\text { (95\% Cl) }\end{array}$ & Event & $\begin{array}{l}\text { Person years } \\
\text { of exposure }\end{array}$ & $\begin{array}{l}\text { Incidence rate } \\
(95 \% \mathrm{CI})\end{array}$ & Event & $\begin{array}{l}\text { Person years } \\
\text { of exposure }\end{array}$ & $\begin{array}{l}\text { Incidence rate } \\
(95 \% \mathrm{CI})\end{array}$ & Event & $\begin{array}{l}\text { Person years } \\
\text { of exposure }\end{array}$ & $\begin{array}{l}\text { Incidence } \\
\text { rate }(95 \% \mathrm{CI})\end{array}$ \\
\hline $\begin{array}{l}\text { Non-biological } \\
\text { DMARDs }\end{array}$ & 5 & 2.272 & $\begin{array}{l}2.20 \\
\text { (0.27 to } 4.13 \text { ) }\end{array}$ & 8 & 2.287 & $\begin{array}{l}3.53 \\
\text { (1.09 to } 5.97)\end{array}$ & 4 & 2.264 & $\begin{array}{l}1.77 \\
(0.04 \text { to } 3.50)\end{array}$ & 17 & 2.264 & $\begin{array}{l}7.51 \\
\text { (3.95 to 11.07) }\end{array}$ \\
\hline Methotrexate & 17 & 7.153 & $\begin{array}{l}2.38 \\
\text { (1.26 to } 3.51)\end{array}$ & 23 & 7.143 & $\begin{array}{l}3.22 \\
\text { (1.91 to } 4.53)\end{array}$ & 8 & 7.132 & $\begin{array}{l}1.12 \\
(0.35 \text { to } 1.90)\end{array}$ & 48 & 7.132 & $\begin{array}{l}6.73 \\
\text { (4.83 to } 8.63 \text { ) }\end{array}$ \\
\hline TNF antagonist & 4 & 7.853 & $\begin{array}{l}0.51 \\
\text { (0.01 to } 1.01)\end{array}$ & 14 & 7.841 & $\begin{array}{l}1.79 \\
(0.85,2.72)\end{array}$ & 5 & 7.837 & $\begin{array}{l}1.02 \\
(0.31 \text { to } 1.73)\end{array}$ & 23 & 7.837 & $\begin{array}{l}2.93 \\
\text { (1.74 to } 4.13 \text { ) }\end{array}$ \\
\hline
\end{tabular}

Incidence rates expressed per 1000 patient years of exposure.

*Composite includes myocardial infarction (MI), transient ischaemic attack (TIA)/stroke and cardiovascular-related deaths.

DMARDs, disease-modifying antirheumatic drugs; TNF, tumour necrosis factor. 
Table 3 Adjusted risk of composite* cardiovascular events by DMARD and steroid exposure

\begin{tabular}{lcll}
\hline & Exposure periods (N) & HR & 95\% Cl \\
\hline TNF antagonists & 4585 & 0.39 & 0.19 to 0.82 \\
Methotrexate & 4791 & 0.94 & 0.49 to 1.80 \\
Other non-biological DMARDs & 1724 & Referent & - \\
$\begin{array}{l}\text { Prednisone } \\
\text { None }\end{array}$ & & & \\
$\quad<7.5 \mathrm{mg}$ daily & 6689 & Referent & - \\
$\quad 7.5 \mathrm{mg}$ daily & 3141 & 1.78 & 1.06 to 2.96 \\
& 1090 & 2.62 & 1.29 to 5.31 \\
\hline
\end{tabular}

Adjusted for age, gender, smoking status, diabetes, hypertension, dyslipidemia, previous myocardial infarction (MI) or stroke and modified health assessment questionnaire score, aspirin use, naproxen use, non-selective non-steroidal antiinflammatory drug use and cyclooxygenase-2 inhibitor use.

*Composite includes MI, transient ischaemic attack/stroke and cardiovascular-related deaths.

DMARDs, disease-modifying antirheumatic drugs; TNF, tumour necrosis factor.

Published studies of the association of biological DMARDs with the risk of MI and/or stroke outcomes have predominantly not observed a risk reduction for patients prescribed TNF antagonists. ${ }^{5}$ 21-23 The largest study to date examined the risk of MI associated with various RA therapies using a large US database reporting patient-derived drug exposure and outcomes. ${ }^{5}$ The authors of that study observed no risk reduction for users of TNF antagonists, with or without background methotrexate use. Two retrospective studies of healthcare utilisation data also failed to observe a risk reduction for biological agents. ${ }^{22} 23$ Of note, investigators from the UK found no overall difference in the risk of MI associated with TNF antagonist use compared with non-biological DMARDs. ${ }^{21}$ However, in that study, TNF antagonist users who demonstrated a robust clinical response appeared to have a reduced risk of MI compared with nonresponders. Other promising data have been reported from a small Swedish study in which a non-significant reduction in the standardised morbidity ratio for cardiovascular-related hospitalisations was observed for patients on TNF antagonists. However, the hospitalisations included congestive heart failure and other non-ischaemic events, and did not adjust for traditional cardiovascular risk factors. ${ }^{24}$ In addition, fewer non-fatal ischaemic events and a non-significant reduction in cardiovascular-related deaths was also reported in TNF antagonist users in a Spanish registry. ${ }^{25}$

The conflicting results of previously published studies relative to our findings may be explained by a number of factors. First, there are differences in the cardiovascular outcome definitions across studies. Second, the comparator cohorts differ across studies. For example, methotrexate monotherapy was selected as the comparator cohort in one large US-based study. ${ }^{22}$ However, methotrexate has previously been observed to reduce cardiovascular mortality, suggesting that the selection of methotrexate as the referent cohort may reduce a study's ability to detect a reduction in risk. ${ }^{37}$ In contrast, a Canadian study defined the reference group as RA patients not prescribed any DMARD. ${ }^{23}$ Additional sources of variability include whether the study design limits drug exposure to new (incident) users, as well as the duration of follow-up. Some studies utilised patient questionnaires or administrative datasets that may not adequately adjust for RA disease activity and severity.

Our study confirms previous observations of a dose-dependent cardiovascular risk for prednisone use in RA patients. ${ }^{5} 38$ However, the threshold for observing an increased cardiovascular risk differs across the studies, as did the patient populations, study periods and endpoint definitions. Consistent with our study results, a US population-based RA study reported
Table 4 Comparison of results for association of TNF antagonists with individual and composite cardiovascular endpoints

\begin{tabular}{lcll}
\hline Endpoint & No of events (N) & HR & $\mathbf{9 5 \%} \mathbf{C l}$ \\
\hline $\begin{array}{l}\text { Composite endpoint (including } \\
\text { cardiovascular deaths) }\end{array}$ & 82 & 0.39 & 0.19 to 0.82 \\
$\begin{array}{l}\text { Composite endpoint (excluding } \\
\text { cardiovascular deaths) }\end{array}$ & 66 & 0.35 & 0.16 to 0.74 \\
$\begin{array}{l}\text { Non-fatal Ml } \\
\text { Non-fatal TIA/stroke }\end{array}$ & 25 & 0.24 & 0.06 to 0.95 \\
\hline
\end{tabular}

All HR reflect fully adjusted models for each endpoint, adjusting for age, gender, smoking status, diabetes, hypertension, dyslipidaemia, previous myocardial infarction (MI) or stroke, modified health assessment questionnaire score, naproxen use, nonselective non-steroidal anti-inflammatory drug use and cyclooxygenase-2 inhibitor use.

TIA, transient ischaemic attack; TNF, tumour necrosis factor.

that prednisone doses greater than $7.5 \mathrm{mg}$ daily were associated with an increased risk of cardiovascular events, defined as MI, heart failure or cardiovascular-related death. ${ }^{38}$ Wolfe and Michaud ${ }^{5}$ focused on the risk of MI in a US cohort study of RA patients, and also observed a dose-dependent risk with prednisone, including a $70 \%$ increased risk for doses of 1-5 mg daily. In fact, the risk estimate of prednisone 1-7 mg daily in our study was very similar (HR 1.78, 95\% CI 1.06 to 2.96). It is possible that residual confounding may exist, particularly for datasets in which steroid use may be a surrogate for RA disease severity.

The strengths of our study include the large cohort of RA patients with detailed clinical and drug information derived from both physicians and patients at the time of a clinical encounter. The large cohort of patients treated with TNF antagonists, as well as methotrexate and non-biological DMARDs, allowed for large study and comparator cohorts for our models. In addition, the inclusion of both traditional cardiovascular risk factors and measures of RA severity and disease activity in the CORRONA registry permitted us to examine and adjust for a large number of relevant potential confounders. Finally, all of the incident cardiovascular events were confirmed with the rheumatology investigator site, and hospital records were obtained on the majority of cases. The results of the adjudicated cardiovascular events using hospital records strengthened our confidence in the validity of our study results, and sensitivity analyses limited to adjudicated cases were consistent with our primary findings.

There are also a number of limitations that should be acknowledged. As is the case with all observational studies, residual confounding including confounding by indication is possible. Although we were able to examine a broad range of potential confounders including traditional cardiovascular risk factors such as the presence of diagnosed hypertension and treated hyperlipidaemia, as well as measures of RA severity, we do not have information about actual blood pressure or lipid measurements. Other types of study bias, including selection bias, also represent potential methodological challenges. In addition, we observed a small number of cardiovascular events, limiting our statistical power for secondary outcomes. An additional limitation was missing data for acute phase reactants that are not mandated in the registry. Finally, the study definition for drug exposures was based on current drug use, which may introduce bias from left censored data. However, sensitivity analyses including a new user design generated similar risk estimates, suggesting our study results are robust. Our study population was primarily Caucasian and derived from a US-based cohort of RA patients with a higher prevalence of TNF antagonist use than most European countries. These realities may limit the generalisability of our findings.

In summary, the use of TNF antagonists for the treatment of RA was associated with a reduced risk of cardiovascular events 
Table 5 Sensitivity analyses of risk of composite cardiovascular endpoint associated with TNF antagonist use

\begin{tabular}{|c|c|c|c|}
\hline Sensitivity analysis & No of events (N) & HR & $95 \% \mathrm{Cl}$ \\
\hline Adjudicated cardiovascular events only & 48 & 0.21 & 0.09 to 0.48 \\
\hline Shorter drug exposure period & 74 & 0.39 & 0.19 to 0.79 \\
\hline Shorter follow-up for cardiovascular deaths* & 72 & 0.39 & 0.19 to 0.82 \\
\hline Longer follow-up for cardiovascular deaths ${ }^{\dagger}$ & 78 & 0.33 & 0.17 to 0.64 \\
\hline $\begin{array}{l}\text { Longer follow-up interval for non-fatal } \\
\text { cardiovascular events }\end{array}$ & 83 & 0.35 & 0.18 to 0.67 \\
\hline New drug users only & 24 & 0.45 & 0.13 to 1.56 \\
\hline RF-positive patients only & 41 & 0.57 & 0.22 to 1.43 \\
\hline Limit to 12-month follow-up & 37 & 0.33 & 0.14 to 0.78 \\
\hline Forced in baseline CDAI & 75 & 0.32 & 0.16 to 0.64 \\
\hline $\begin{array}{l}\text { Exclude patients with previous } \\
\text { cardiovascular disease }\end{array}$ & 67 & 0.32 & 0.15 to 0.66 \\
\hline Anti-TNF monotherapy & 83 & 0.63 & 0.27 to 1.49 \\
\hline Anti-TNF combination therapy & 83 & 0.28 & 0.14 to 0.60 \\
\hline Exclude patients with history of anti-TNF use & 68 & 0.57 & 0.22 to 1.48 \\
\hline $\begin{array}{l}\text { Exclude person time after switching drug } \\
\text { exposure category }\end{array}$ & 64 & 0.30 & 0.14 to 0.63 \\
\hline $\begin{array}{l}\text { Maintain initial drug exposure category after } \\
\text { drug switch }\end{array}$ & 64 & 0.41 & 0.19 to 0.85 \\
\hline
\end{tabular}

The composite cardiovascular endpoint includes myocardial infarction (MI), transient ischaemic attack/stroke and cardiovascular-related deaths. All HR reflect fully adjusted models for each endpoint, adjusting for age, gender, smoking status, diabetes, hypertension, dyslipidaemia, previous MI or stroke, modified health assessment questionnaire score, aspirin use, naproxen use, non-selective non-steroidal antiinflammatory drug (NSAID) use and cyclooxygenase-2 inhibitor use.

* Shorter follow-up interval ( $<90$ days) after last study visit for cardiovascular death ascertainment.

${ }^{\dagger}$ Longer follow-up interval (no limit) after last study visit for cardiovascular death ascertainment.

CDAl, clinical disease activity index; RF, rheumatoid factor; TNF, tumour necrosis factor.

compared with non-biological DMARDs. We confirmed the association of a dose-dependent risk of corticosteroids. TNF antagonist drugs may represent a promising therapeutic strategy to attenuate the heightened cardiovascular risk associated with RA. Further population-based and/or interventional studies of cytokine blockade are needed to determine the role of inflammation in driving cardiovascular events in populations at risk.

Acknowledgements The authors wish to thank Drs Simonette Sawit and Sameer Bansilal for their contributions as part of the cardiovascular adjudication committee with Dr Michael Farkouh.

Funding The study design, data analysis and reporting of results in this manuscript were performed independent of all funding sources. This work was funded by an Arthritis Clinical Translational Research Award in Rheumatoid Arthritis from the Arthritis Foundation (JDG). In the past 2 years, CORRONA has received general support from Abbott, Amgen, BMS, Centocor, Genentech, Lilly and Roche. Amgen and Centocor had supported an earlier project that was presented as an abstract at the 2006 Annual Scientific Meeting of the American College of Rheumatology, 13 November 2006 in Washington, DC, USA.

Competing interests JDG receives salary support from research grants from the National Institutes of Health (NIH) (K23AR054412), the Arthritis Foundation and Bristol Myers Squibb, he serves as chief scientific officer for CORRONA and has served on advisory boards for BMS, Centocor, Genentech, Roche and UCB. JRC receives salary support from NIH (AR053351) and the Agency for Healthcare Research and Quality (AHRO) (R01HS018517) and research/consulting support from Genentech/Roche, Amgen, UCB, Centocor and BMS. DHS receives salary support from research grants from the NIH (AR055989 and AR047782), AHRO, the Arthritis Foundation, Abbott and Amgen. GR has a research contract with CORRONA. Research support has been provided to JMK by Amgen, Abbott, Centocor, BMS, Roche and Genentech as well as honoraria from Abbott, Centocor, BMS, Roche and Genentech. MCH served as a consultant for Amgen, Bristol Meyers Squibb, Roche and UCB. PT, AN and MEF have declared no competing interests.

Patient consent Obtained.

Ethics approval This study was approved by the institutional review boards of participating academic sites and a central institutional review board for communitybased private sites.

Provenance and peer review Not commissioned; externally peer reviewed.

\section{REFERENCES}

1. Solomon DH, Goodson NJ, Katz JN, et al. Patterns of cardiovascular risk in rheumatoid arthritis. Ann Rheum Dis 2006;65:1608-12.

2. Maradit-Kremers H, Nicola PJ, Crowson CS, et al. Cardiovascular death in rheumatoid arthritis: a population-based study. Arthritis Rheum 2005;52:722-32.

3. Solomon DH, Karlson EW, Rimm EB, et al. Cardiovascular morbidity and mortality in women diagnosed with rheumatoid arthritis. Circulation 2003:107:1303-7.

4. del Rincón ID, Williams K, Stern MP, et al. High incidence of cardiovascular events in a rheumatoid arthritis cohort not explained by traditional cardiac risk factors. Arthritis Rheum 2001;44:2737-45

5. Wolfe F, Michaud K. The risk of myocardial infarction and pharmacologic and nonpharmacologic myocardial infarction predictors in rheumatoid arthritis: a cohort and nested case-control analysis. Arthritis Rheum 2008;58:2612-21.

6. Del Rincón I, Williams K, Stern MP, et al. Association between carotid atherosclerosis and markers of inflammation in rheumatoid arthritis patients and healthy subjects. Arthritis Rheum 2003:48:1833-40.

7. Goodson NJ, Symmons DP, Scott DG, et al. Baseline levels of C-reactive protein and prediction of death from cardiovascular disease in patients with inflammatory polyarthritis: a ten-year followup study of a primary care-based inception cohort. Arthritis Rheum 2005;52:2293-9.

8. Van Doornum S, McColl G, Wicks IP. Accelerated atherosclerosis: an extraarticular feature of rheumatoid arthritis? Arthritis Rheum 2002;46:862-73.

9. Ridker PM, Hennekens $\mathrm{CH}$, Buring JE, et al. C-reactive protein and other markers of inflammation in the prediction of cardiovascular disease in women. N Engl J Med 2000;342:836-43

10. Ridker PM, Rifai N, Pfeffer M, et al. Elevation of tumor necrosis factor-alpha and increased risk of recurrent coronary events after myocardial infarction. Circulation 2000;101:2149-53.

11. Ross R. Atherosclerosis - an inflammatory disease. N Engl J Med 1999;340:115-26.

12. Hochberg MC, Lebwohl MG, Plevy SE, et al. The benefit/risk profile of TNF-blocking agents: findings of a consensus panel. Semin Arthritis Rheum 2005;34:819-36.

13. Gartlehner G, Hansen RA, Jonas BL, et al. The comparative efficacy and safety of biologics for the treatment of rheumatoid arthritis: a systematic review and metaanalysis. J Rheumatol 2006;33:2398-408.

14. Feldmann M, Maini RN. Anti-TNF alpha therapy of rheumatoid arthritis: what have we learned? Annu Rev Immunol 2001:19:163-96.

15. Gonzalez-Gay MA, De Matias JM, Gonzalez-Juanatey C, et al. Anti-tumor necrosis factor-alpha blockade improves insulin resistance in patients with rheumatoid arthritis. Clin Exp Rheumatol 2006;24:83-6.

16. Popa C, Netea MG, Radstake T, et al. Influence of anti-tumour necrosis factor therapy on cardiovascular risk factors in patients with active rheumatoid arthritis. Ann Rheum Dis 2005;64:303-5.

17. Tam LS, Tomlinson B, Chu TT, et al. Impact of TNF inhibition on insulin resistance and lipids levels in patients with rheumatoid arthritis. Clin Rheumatol 2007:26:1495-8.

18. Hürlimann D, Forster A, Noll G, et al. Anti-tumor necrosis factor-alpha treatment improves endothelial function in patients with rheumatoid arthritis. Circulation 2002:106:2184-7.

19. Mäki-Petäjä KM, Hall FC, Booth $A D$, et al. Rheumatoid arthritis is associated with increased aortic pulse-wave velocity, which is reduced by anti-tumor necrosis factoralpha therapy. Circulation 2006;114:1185-92.

20. Del Porto $\mathbf{F}$, Laganà $\mathrm{B}$, Lai $\mathrm{S}$, et al. Response to anti-tumour necrosis factor alpha blockade is associated with reduction of carotid intima-media thickness in patients with active rheumatoid arthritis. Rheumatology (Oxford) 2007:46:1111-15.

21. Dixon WG, Watson KD, Lunt $M$, et al. Reduction in the incidence of myocardial infarction in patients with rheumatoid arthritis who respond to anti-tumor necrosis factor alpha therapy: results from the British Society for Rheumatology Biologics Register. Arthritis Rheum 2007;56:2905-12.

22. Solomon DH, Avorn J, Katz JN, et al. Immunosuppressive medications and hospitalization for cardiovascular events in patients with rheumatoid arthritis. Arthritis Rheum 2006;54:3790-8.

23. Suissa S, Bernatsky S, Hudson M. Antirheumatic drug use and the risk of acute myocardial infarction. Arthritis Rheum 2006;55:531-6.

24. Jacobsson LT, Turesson C, Gülfe A, et al. Treatment with tumor necrosis factor blockers is associated with a lower incidence of first cardiovascular events in patients with rheumatoid arthritis. J Rheumatol 2005;32:1213-18.

25. Carmona L, Descalzo MA, Perez-Pampin E, et al., BIODASER and EMECAR Groups. All-cause and cause-specific mortality in rheumatoid arthritis are not greater than expected when treated with tumour necrosis factor antagonists. Ann Rheum Dis 2007:66:880-5.

26. Kremer J. The CORRONA database. Ann Rheum Dis 2005;64(Suppl 4):iv37-41.

27. Kremer JM. The CORRONA database. Clin Exp Rheumatol 2005;23(5 Suppl 39):S172-7.

28. Felson DT, Anderson JJ, Boers M, et al. American College of Rheumatology. Preliminary definition of improvement in rheumatoid arthritis. Arthritis Rheum 1995; 38:727-35.

29. Farkouh ME, Kirshner $\mathrm{H}$, Harrington RA, et al. Comparison of lumiracoxib with naproxen and ibuprofen in the Therapeutic Arthritis Research and Gastrointestinal Event Trial (TARGET), cardiovascular outcomes: randomised controlled trial. Lancet 2004;364:675-84. 
30. Pincus T, Summey JA, Soraci SA, Jr, et al. Assessment of patient satisfaction in activities of daily living using a modified Stanford Health Assessment Questionnaire. Arthritis Rheum 1983;26:1346-53.

31. Prevoo ML, van 't Hof MA, Kuper HH, et al. Modified disease activity scores that include twenty-eight-joint counts. Development and validation in a prospective longitudinal study of patients with rheumatoid arthritis. Arthritis Rheum 1995:38:44-8.

32. Barath $\mathbf{P}$, Fishbein $\mathrm{MC}$, Cao J, et al. Detection and localization of tumor necrosis factor in human atheroma. Am J Cardiol 1990;65:297-302.

33. Herskowitz A, Choi S, Ansari AA, et al. Cytokine mRNA expression in postischemic/ reperfused myocardium. Am J Pathol 1995;146:419-28.

34. Dixon WG, Symmons DP. What effects might anti-TNFalpha treatment be expected to have on cardiovascular morbidity and mortality in rheumatoid arthritis? A review of the role of TNFalpha in cardiovascular pathophysiology. Ann Rheum Dis 2007;66:1132-6.

35. Ridker PM, Rifai N, Stampfer MJ, et al. Plasma concentration of interleukin-6 and the risk of future myocardial infarction among apparently healthy men. Circulation 2000;101:1767-72

36. Gonzalez-Juanatey C, Testa A, Garcia-Castelo A, et al. Active but transient improvement of endothelial function in rheumatoid arthritis patients undergoing long-term treatment with anti-tumor necrosis factor alpha antibody. Arthritis Rheum 2004;51:447-50.

37. Choi HK, Hernán MA, Seeger JD, et al. Methotrexate and mortality in patients with rheumatoid arthritis: a prospective study. Lancet 2002;359:1173-7.

38. Davis JM, III, Maradit Kremers H, Crowson CS, et al. Glucocorticoids and cardiovascular events in rheumatoid arthritis: a population-based cohort study. Arthritis Rheum 2007;56:820-30. 